\title{
Aerogels: a fascinating class of materials with a wide potential of application fields
}

\author{
Arnaud Rigacci $^{1} \cdot$ Tatiana Budtova $^{1} \cdot$ Irina Smirnova $^{2}$
}

Published online: 10 November 2017

(C) Springer Science+Business Media, LLC 2017

In September 2016, the "Third International Seminar on Aerogels", co-organized with the International Society for the Advancement of Supercritical Fluids (ISASF) and Technical University of Hamburg-Harburg (TUHH) was hosted by MINES ParisTech in Sophia Antipolis (AlpesMaritimes, France). This Special Issue gathers 17 full original articles related to topics and presentations of this event.

Aerogels are not brand new materials despite being still considered as emerging ones. Since the pioneering work of Samuel Kistler [1], they have been then increasingly studied to such an extent that a scientific international community is born. Amongst various scientific and technological achievements, substitution of waterglass with alcoxysilanes was one of the major breakthroughs as well as replacement of liquid phase trapped in the porosity with $\mathrm{CO}_{2}$ before drying step. The First International Symposium on Aerogels (ISA) was then organized in Würzburg (Germany) by Professor Jochen Fricke in $1985 .{ }^{1}$ These ISA conferences have structured the research on aerogels bringing together academic and industrial actors from all over the world of this promising and exciting sector. This sequence of

Arnaud Rigacci

arnaud.rigacci@mines-paristech.fr

1 MINES ParisTech, PSL Research University, Sophia Antipolis, France

2 TU Hamburg-Harburg, Hamburg, Germany

\footnotetext{
${ }^{1}$ Aerogels (1985) Proceedings in Physics 6. In: Fricke J (ed.) Proceedings of the First International Symposium, Würzburg, Federal Republic of Germany, 23-25 September 1985. Springer, ISBN 3-54016256-9.
}

exchanges stopped in 2003 with ISA7, the last event of this series of conference held in Alexandria (VA, USA). During these two decades (1985-2003) many major advances were realized amongst which is "spring-back effect". Silylation of pore walls allowed obtaining lightweight and thermally superinsulating silica-based matrices by an evaporative processing route in mild conditions as an alternative to supercritical drying.

Despite this historical blow, aerogels continued to be intensively studied both at laboratory and industrial scales. Aerogels' unique textural characteristics (nanostructured solid phase, mesoporosity, low density, fractality,...), their extraordinary physical properties (extremely low thermal conductivity, very high specific surface,...$)$, their "chemical flexibility" (from mineral to organic systems through organic-inorganic hybridization) and their varied shaping (powders, films, granules, blankets, monoliths,...) together with their wide potential for applications in strategic fields like energy, environment, health, etc, have continued to mobilize the efforts of main historical industrial players (e.g., Cabot, Aspen Aerogels) while creating a new academic and industrial dynamics. New actors entered the game (e.g., BASF, Aerogel Technologies, Nano High-Tech, Enersens, KEEY Aerogels), brand new fields appeared (like bio-based aerogels), the very first fully dedicated Handbook was published. ${ }^{2}$ In the early 2010 's, there was a clear need for a re-foundation of the aerogels' international community.

Under the impetus of Irina Smirnova (TUHH, Germany) and Michel Perrut (ISASF, France) a new cycle of international conferences on aerogels was launched. After

\footnotetext{
2 Aerogels Handbook (2011) Aegerter MA, Leventis N, Koebel MK (eds) Advances in sol-gel derived materials and technologies. Springer, ISBN 978-1-4419-7477-8.
} 
gathering around 70 participants in Nancy (6-7 December 2012) and 130 in Hamburg (6-7 October 2014), ${ }^{3}$ the Third International Seminar on Aerogels has passed the milestone of 160 congress participants in Sophia Antipolis, France, coming from all over the world. This continuous growing international audience is a direct demonstration of the revival of interest to aerogels' research and applications.

The third Aerogels conference addressed a large variety of topics such as synthesis and functionalisation, processing and process modeling, aerogels for catalysis and energy, the latter with a specific zoom on thermal (super)insulation. Three sessions were also organized on bio-aerogels and their composites, brand new materials attracting a lot of interest. This clearly represents one the main trends of the last decade where bio-based aerogels are now somehow competing with silica-based matrices for a significant set of applicative fields and appear to be studied more and more each year. Finally, a full session was dedicated to presentations from industry. In total, $>60$ oral presentations and 65 poster communications were presented during these "aerogels days" on the French Riviera.

Based on the multiple topics at the conference, the current special issue compiles studies on synthesis (for example, preparation of silica-based aerogels with propylene oxides as reactants (Lermontov et al.) or alginate-based composites with multiwalls carbon nanotubes (Menshutina et al.)), characterization (holotomography to study internal texture of resorcinol-formaldehyde aerogels (Tannert et al.)) and processing (thermodynamic study of $\mathrm{CO}_{2}$ /solvent separation for organic gels drying (Lazrag et al.),...); studies for applications to catalysis (isomerization of styrene oxide (Shalygin et al.)), environmental concerns (adsorption of heavy metals (Vareda and Duares) and phenolic compounds (Matias et al.), adsorption for automotive pollution mitigation (Tobin et al.) and $\mathrm{CO}_{2}$ capture (Kong et al.)), thermal (super) insulation (thermal coupling effects on thermal conductivity of organic aerogels (Swimm et al.), freeze-drying impacts on thermal conductivity of cellulose aerogels (Jimenez-Saelices et al.), realization of silica-based composite aerogels using paper honeycomb (Berkefeld et al.), preparation of aluminabased aerogels for highly efficient insulation at high temperatures (Zou et al.)), energy storage (carbon xerogels for supercapacitor electrodes (Annamalai et al.)) and physics (silica aerogels for optofuidic waveguides (Özbakir et al.)); and also aerogel art (Michaloudis).

This collection shows how dynamic the international scientific community on aerogels is again. However, studies have to be continued at laboratory scale to go on improving processing and properties. For instance, it remains clear that costs of aerogels production have to be cut off, mechanical properties of silica-based aerogels have to be improved paying particular attention to dust release, alternative drying routes have to be studied for organic families (including bio-aerogels), ageing is now to be really addressed. All these and much more aspects will be discussed in Hamburg in 2018 within the frame of the Fourth International Seminar on Aerogels. We do hope that our community will grow up by then and that new scientific, technological and applicative milestones will be achieved.

We should like to finish these introductory remarks by warmly thanking prof. Michel A. Aegerter, Editor-in-Chief of The Journal of Sol-Gel Science and Technology, as well as Springer, for the support to the preparation and hosting of this "Aerogels" Special Issue. We also want to address our warmest thanks to our sponsors Communauté d'Agglomération Sophia Antipolis (CASA), Aerogel Technologies, Aspen Aerogels, BASF, Enersens, Natex, Parex Group and MINES ParisTech, as well as ISASF for organizational support.

\section{Reference}

1. Kistler SS (1932) Coherent expanded aerogels. J Phys Chem 63: $52-64$

\footnotetext{
3 Aerogels (2015): synthesis and applications. J Supercrit Fluids, 106: $1-166$. 